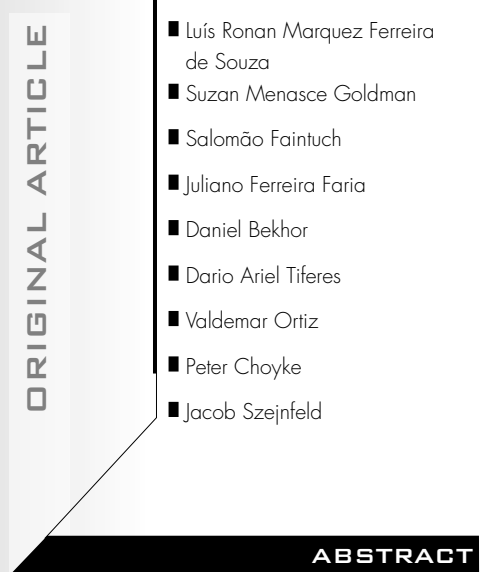

CONTEXT AND OBJECTIVE: Recent studies have shown noncontrast computed tomography (NCT) to be more effective than ultrasound (US) for to be more effective than ultrasound (US) for
imaging acute ureterolithiasis. However, to our imaging acute ureterolithiasis. However, to our knowledge, there are few studies directly comparing these techniques in an emergency teaching to compare the diagnostic accuracy of US and NCT performed by senior radiology residents for diagnosing acute ureterolithiasis; and to assess interobserver agreement on tomography interpretations by residents and experienced abdominal radiologists.

DESIGN AND SETTING: Prospective study of 52 consecutive patients, who underwent both US and NCT within an interval of eight hours, at Hospital São Paulo.

METHODS: US scans were performed by senior residents and read by experienced radiologists. NCT scan images were read by senior residents, and subsequently by three abdominal radiologists. The interobserver variability was assessed using the kappa statistic.

RESULTS: Ureteral calculi were found in 40 out of 52 patients $(77 \%)$. US presented sensitivity of $22 \%$ and specificity of $100 \%$. When collecting system dilatation was associated, US $2 \%$ specificity. The interobserver agreement in NCT analysis was very high with regard to identification of calculi, collecting system dilatation and stranding of perinephric fat.

CONCLUSIONS: US has limited value for identify ing ureteral calculi in comparison with NCT, even when collecting system dilatation is present. Residents and abdominal radiologists demonstrated excellent agreement rates for ureteral calculi, identification of collecting system dilatation and stranding of perinephric fat on NCT.

KEY WORDS: Spiral computed tomography Ultrasonography. Ureteral calculi. Lithiasis Flank pain.

\title{
Comparison between ultrasound and noncontrast helical computed tomography for identification of acute ureterolithiasis in a teaching hospital setting
}

Diagnostic Imaging Department, Universidade Federal de São Paulo - Escola Paulista de Medicina (Unifesp-EPM), São Paulo, Brazil

INTREDUCTION

Since its first introduction by Smith et al. in $1995,{ }^{1}$ noncontrast helical computed tomography (NCT) has evolved into a tool for rapid examination of patients suspected of having ureterolithiasis, without the limitations of plain films, intravenous urography and ultrasound..$^{2-4}$ NCT has become the method of choice for evaluating patients with acute renal colic. ${ }^{5-8}$

Transabdominal ultrasound (US) has the advantages of being universally available, not exposing the patient to radiation and being independent of kidney function. ${ }^{9-10}$ Because of these advantages, US is preferred by referring clinicians for evaluating acute renal colic.

Recent studies ${ }^{9-11}$ have shown NCT to be more effective than US for imaging ureterolithiasis in patients with acute renal colic. However, to our knowledge, there are few studies directly comparing these techniques in an emergency teaching hospital setting. ${ }^{12}$

\section{口BJECTIVE}

The twofold purpose of our study was to compare the diagnostic sensitivity of US and NCT performed by radiology residents for diagnosing ureterolithiasis, in patients with acute renal colic; and to assess interobserver agreement regarding NCT interpretation by a group of senior residents and experienced radiologists.

METHODS

Between February and July 2002, we conducted a prospective study on 52 consecutive patients referred from our emergency department for evaluation of acute renal colic. Renal colic was defined as a painful symptom relating to possible obstruction of the collecting system that started as an acute flank pain and which made the patient seek medical help.

The study protocol had previously been approved by our institutional ethics committee and all patients gave their consent for their participation.
The patients underwent both US and NCT within eight hours of the onset of colic. The exclusion criteria were other known renal diseases or imaging signs of pyelonephritis, chronic renal insufficiency, nephrocalcinosis and staghorn calculus.

The US examination was performed transabdominally, after ingestion of water. Sonography was performed by senior radiology residents and immediately checked by attending radiologists, using a Philips SD800 scanner (Philips Medical Systems, Eindhoven, Netherlands) with a convex (curved phased array) transducer $(2-5 \mathrm{MHz})$ and transducer frequencies selected to optimize the imaging of the kidneys, ureters and bladder. The US diagnosis of ureteral calculi required the demonstration of an intraluminal hyperechoic structure causing acoustic shadowing. The presence of collecting system dilatation was also evaluated. No patient underwent transvaginal or transrectal sonographic examination.

NCT scans were acquired after US examination, on a Tomoscan EV-EV1 (Philips Medical Systems, Eindhoven, Netherlands) using Secura Release 1.3 software. The scan parameters included helical data acquisition, with section thickness 3-5 mm, using $120 \mathrm{kV}$ and $200 \mathrm{mAs}$ and a pitch of 1-1.5. Images were obtained during apnea, from the top of the kidneys to the base of the bladder, and no contrast medium was used. The NCT images were interpreted by a senior resident, using an electronic workstation (Philips), and subsequently reviewed by three experienced abdominal radiologists in a blinded manner.

The NCT scan analysis included identification and localization of ureteral calculi, and evaluation for the presence of the following signs: intrarenal collecting system and/or ureteral dilatation, and stranding of perinephric and periureteral fat. Incidental diagnoses were also recorded. 
Once the three experienced observers had completed their independent reviews for the interobserver investigation, all the cases in which there were disagreements about the presence of collecting system obstruction or ureteral calculi on NCT scans were reevaluated. Any differences were resolved by consensus.

The locations of the calculi were defined as proximal (above the sacroiliac joints, SIJ), mid (overlying the SIJ), distal ureteral (below the SIJ), or at the ureterovesical junction (UVJ). Stone size was measured at the maximum diameter within the plane of the axial CT section; the measurement was made perpendicularly to the course of the ureter, on a workstation. Stones were considered to be definitively present when recovered in urine, extracted during urological procedures or clearly shown by CT interpretation. ${ }^{13}$

Differences in sensitivity and specificity were calculated using the McNemar test. Interobserver variability for the detection of ureteral calculi on US and CT scans was evaluated using the kappa statistic. ${ }^{14} \mathrm{~A}$ p-value of less than 0.05 was taken to indicate a statistically significant difference.

\section{RESULTS}

Among the 52 patients studied, 40 ureteral stones were detected on NCT, thus giving a prevalence of $77 \%$. The locations of the calculi were: UVJ (47\%), proximal (30\%), distal $(18 \%)$ and mid-ureteral (5\%) (Figure 1). The mean calculus size (longest axis) was $5 \mathrm{~mm}$, with a range from $2 \mathrm{~mm}$ to $14 \mathrm{~mm}$. No patient had more than one stone. In all cases, both exams were performed within eight hours, with an average of four hours between US and NCT.
Among the 12 patients who did not have ureteral stones identified by CT, one had infected renal cysts and four were considered to have had spontaneous passage of ureteral calculi, because unilateral collecting system dilatation was found on the symptomatic side, without other image findings. For the remaining seven patients, no definitive diagnosis was possible.

As shown in Table 1, CT read by abdominal radiologists identified 40 calculi, and US demonstrated only nine, thus corresponding to sensitivity of $22 \%$, specificity of $100 \%$ and accuracy of $40 \%$. The agreement between the US performed by the group of senior residents and the NCT read by the experienced radiologists was very low $(\mathrm{k}=0.06)$. In all cases when CT was negative for ureteral stones, the results matched those from US.
When unilateral intrarenal collecting system dilatation was used as an indirect sign of ureteral calculi (Table 2), the sensitivity of US improved to $73 \%$, but the specificity decreased to $82 \%$, with an overall accuracy of $75 \%$. The agreement between US including collecting system dilatation, read by senior residents, and NCT read by the experienced radiologists improved to a moderate level $(\mathrm{k}=0.42)$.

To evaluate the interobserver agreement between residents and experienced abdominal radiologists, we used the kappa statistic and the results are demonstrated in Table 3. The agreement was high for identification of calculi $(\mathrm{k}=0.81)$, collecting system dilatation $(\mathrm{k}=0.75)$ and stranding of perinephric fat $(\mathrm{k}=0.78)$, but moderate for stranding of ureteral fat $(\mathrm{k}=0.41)$ and for ureteral dilatation $(\mathrm{k}=0.46)$.

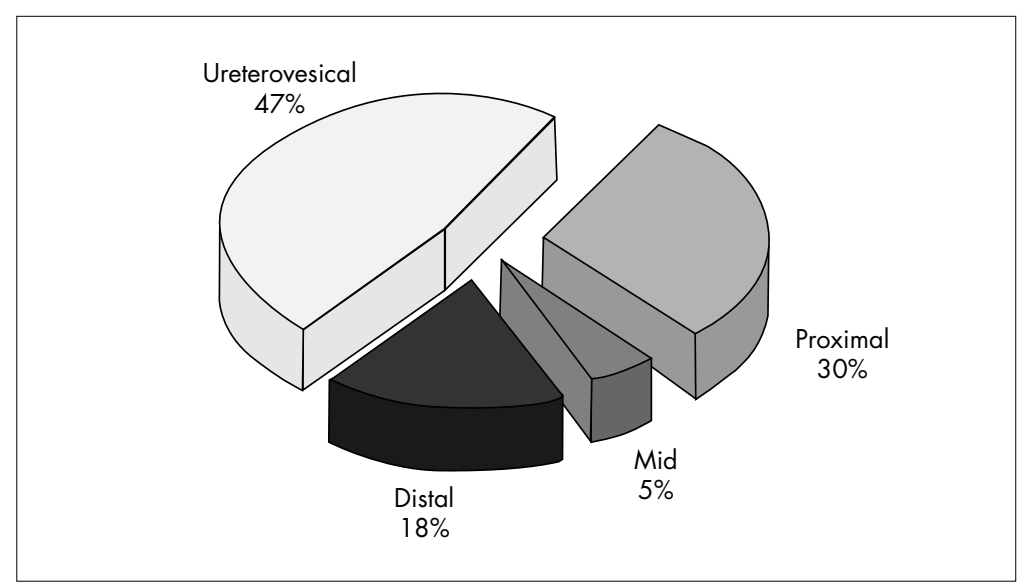

Figure 1. Localization of the 40 ureteral stones founded on noncontrast helical computed tomography of 52 patients.

Table 1. Comparison between ultrasound and noncontrast helical computed tomography for identifying ureteral stone

\begin{tabular}{lccc} 
& NCT positive for ureteral stone & NCT negative for ureteral stone & Total \\
\hline US positive for ureteral stone & 9 & 0 & 9 \\
US negative for ureteral stone & 31 & 12 & 43 \\
Total & $\mathbf{4 0}$ & $\mathbf{1 2}$ & $\mathbf{5 2}$ \\
\hline
\end{tabular}

NCT = noncontrast helical computed tomography; US = ultrasound; $k=0.06(6 \%)$ for agreement between senior residents and experienced radiologists.

Table 2. Comparison between ultrasound and noncontrast helical computed tomography for identifying ureteral stone and/or intrarenal collecting system dilatation

\begin{tabular}{lccc}
\hline & $\begin{array}{c}\text { NCT positive for ureteral stone and/or } \\
\text { intrarenal collecting system dilatation }\end{array}$ & $\begin{array}{c}\text { NCT negative for ureteral stone and/or } \\
\text { intrarenal collecting system dilatation }\end{array}$ & \multicolumn{2}{c}{ Total } \\
\hline $\begin{array}{l}\text { US positive for ureteral stone and/ } \\
\text { or intrarenal collecting system dilatation }\end{array}$ & 30 & 32 \\
$\begin{array}{l}\text { US negative for ureteral stone and/ } \\
\text { or intrarenal collecting system dilatation }\end{array}$ & 11 & 9 & 20 \\
Total & $\mathbf{4 1}$ & $\mathbf{1 1}$ & $\mathbf{5 2}$ \\
\hline
\end{tabular}

$N C T=$ noncontrast helical computed tomography; US = ultrasound; $k=0.42$ (42\%) for agreement between senior residents and experienced radiologists. 


\section{DISCUSSIDN}

Ultrasound has many desirable features as an imaging method. It is inexpensive, does not expose the patient to ionizing radiation and can be performed at the patient's bedside. Unfortunately, the sensitivity of US is highly variable for evaluating patients with acute renal colic and depends on stone size, examiner experience and patient conditions. Fowler et al. ${ }^{15}$ found that US is a poor means for demonstrating stones smaller than 4.0 $\mathrm{mm}$. One of the main disadvantages of US is that the identification of a stone within the ureter is frequently hindered by the patient's body habitus or by obscuring of portions of the ureter due to overlying bowel gas. ${ }^{7,16}$

Training for performing basic US examinations is a quick process for radiology residents. However, a higher level of skill, knowledge and familiarity with US findings is needed when the stones are not at the ureteral junctions, or whenever alternative diagnoses must be made. ${ }^{9}$ Ultrasound is very sensitive in depicting the anatomical changes associated with obstruction of the collecting system. ${ }^{17}$ Nonetheless, we found

Table 3. Interobserver agreement in computed tomography evaluation (residents versus experienced radiologists)

\begin{tabular}{lccc}
\hline & Residents & Experienced radiologists & Kappa \\
\hline Identification of ureteral stone & 36 & 40 & 0.81 \\
Intrarenal collecting system dilatation & 29 & 36 & 0.75 \\
Perinephric fat stranding & 10 & 13 & 0.78 \\
Ureteral dilatation & 16 & 31 & 0.46 \\
Ureteral fat stranding & 3 & 10 & 0.41 \\
\hline
\end{tabular}
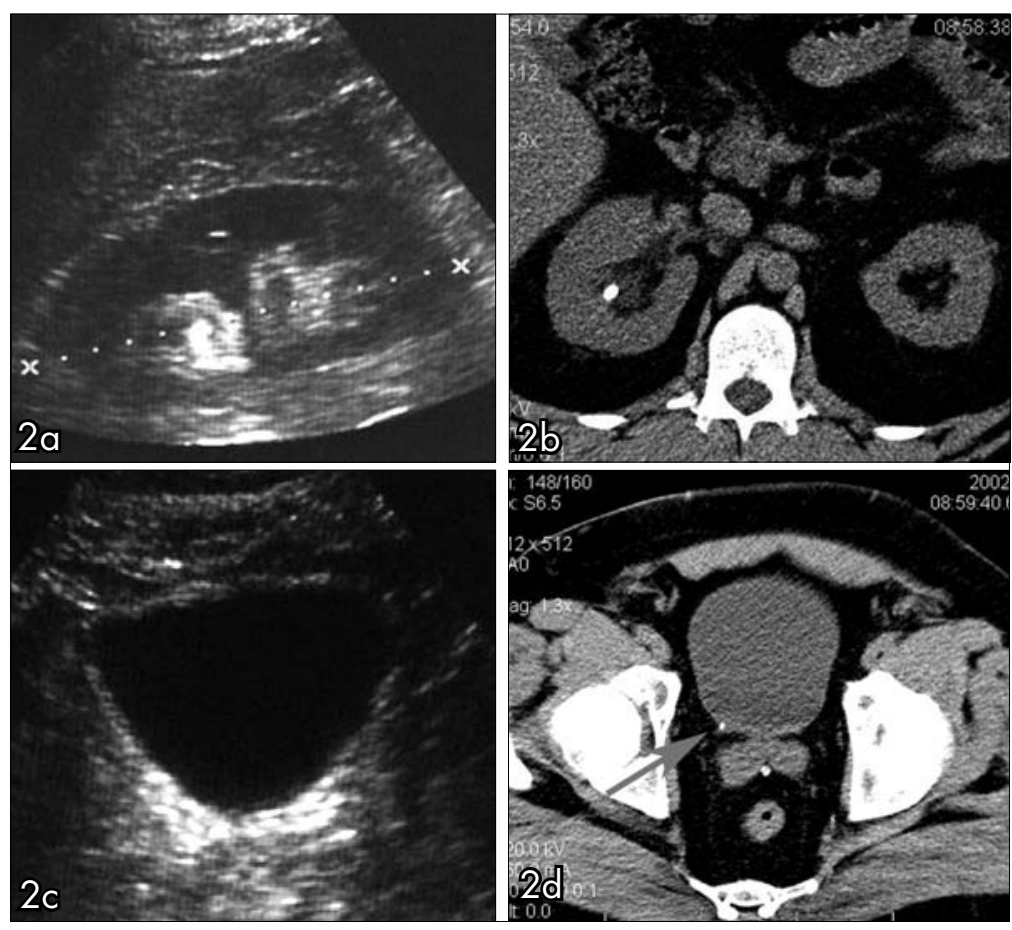

Figure 2. 33-year old man with right-sided renal colic. Noncontrast helical computed tomography (CT) and abdominal ultrasound (US) in the same patient. (a) Coronal identification of the right kidney (between calipers) with a renal stone and mild intrarenal collecting system dilatation. The same findings were found on CT scan (b). In the US scan of the bladder and right ureterovesical junction (c), the radiology resident did not find the small stone $(3 \mathrm{~mm})$, shown in CT (d). that the sensitivity of US was only $22 \%$ in comparison with NCT, which is inadequate for routine use.

The causes of false negative US examinations include minor dilatation of the collecting system during early obstruction, forniceal rupture, extrarenal pelvis and decreased renal output. ${ }^{8}$

In our study, US performed by the group of senior residents presented limited accuracy in comparison with CT read by the experienced observers, for identifying ureteral calculi (Figures 2 and 3). The accuracy of US improved from $40 \%$ to $75 \%$ with the association of unilateral collecting system dilatation as a secondary sign for ureteral calculi. However, the specificity decreased because there were more frequent false positive examinations.

All stones, regardless of their chemical composition, are generally depicted by NCT. It has recently been reported that stones formed as concretions of crystals of protease inhibitor (e.g. indinavir), which are relatively radiolucent, are the only calculi that are undetectable on CT. ${ }^{18-20}$

Unenhanced helical CT is an extremely fast and efficient imaging method. In our institution, the time taken to perform a CT scan was determined to be approximately seven minutes (room time). The test is not affected by the presence of increased amounts of bowel gas or by obesity. ${ }^{20,21}$ Thus, unenhanced helical CT is currently the imaging test of choice for evaluating patients with acute flank pain for whom the clinical diagnosis is uncertain. ${ }^{22-29}$

In the CT evaluation of ureteral calculi, the agreement between the group of senior residents and the consensus among the abdominal radiologists were very good, as shown in Table 3. The interobserver agreement for identifying the ureteral stone was almost perfect $(\mathrm{k}=0.81)$. The findings in our study are concordant with Freed et al., ${ }^{12}$ who found a very good interobserver agreement in evaluations of ureteral stone disease, comparing experienced radiologists with radiology residents $(\mathrm{k}=0.65-0.67)$. To our knowledge, this was the only previous study with such analysis undertaken within a teaching hospital setting.

The two most common secondary signs of ureteral obstruction observed in our study are also the two most commonly reported in the literature. ${ }^{30-31}$ These were intrarenal collecting system dilatation ( $74 \%$ of the cases) and ureteral dilatation (in $71 \%$ of the cases) (Figures 4 and 5). 

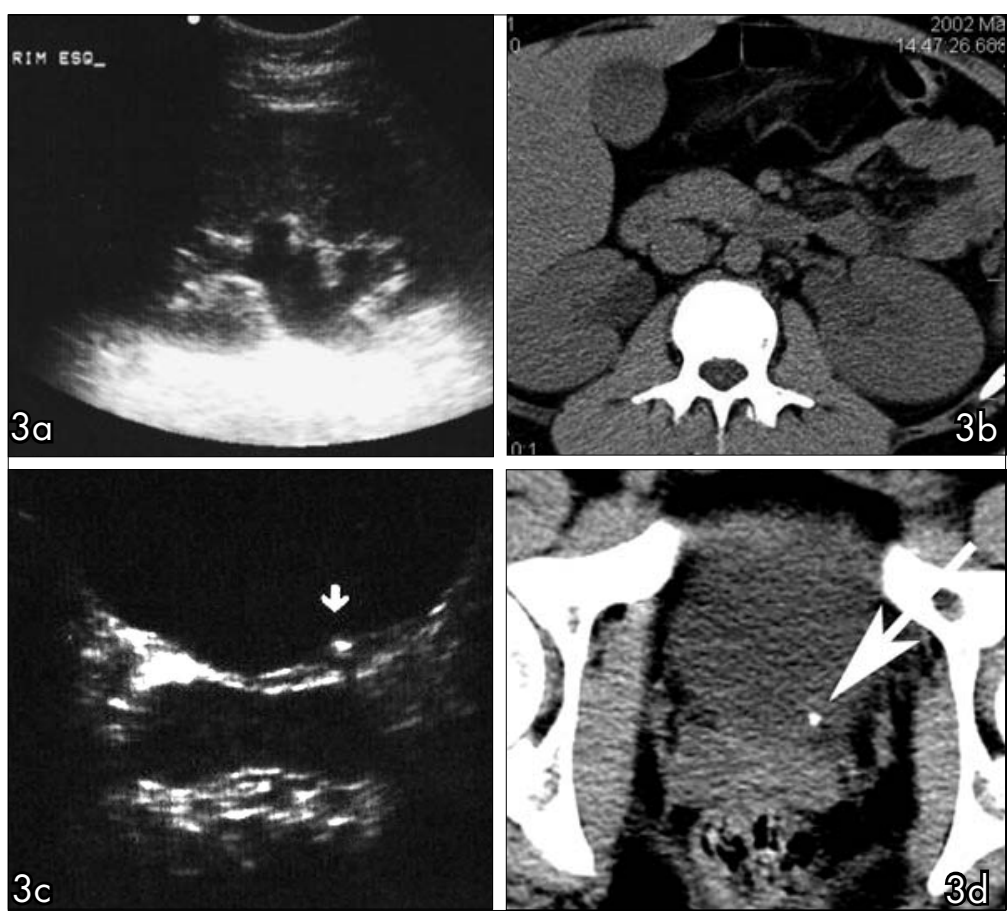

Figure 3. Comparison between ultrasound (US) and computed tomography (NCT) in two different patients. (a) Coronal identification of the left kidney showing collecting system dilatation, which was confirmed in NCT (b). US scan at bladder level showing stone at left ureterovesical junction (arrow in c), confirmed by NCT (d).

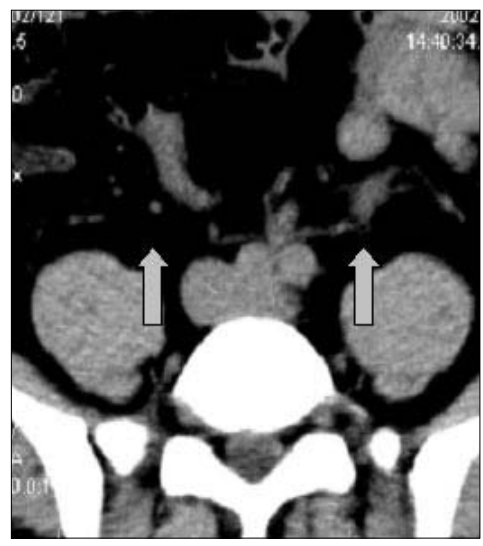

Figure 4. Collecting system dilatation. Noncontrast helical computed tomography (NCT) on a patient with a stone in the distal left ureter, showing ureteral dilatation in comparison with the contralateral normal side (arrows).

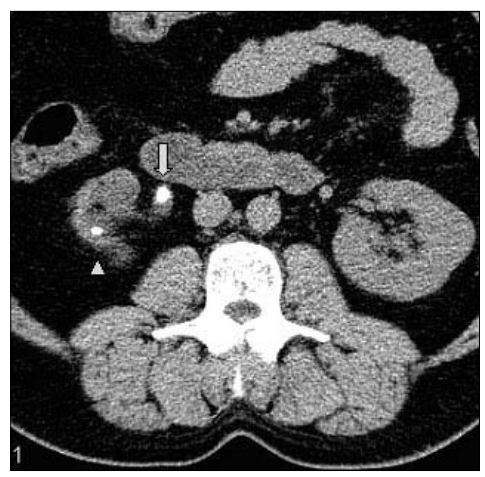

Figure 5. Ureteral fat stranding. Axial slice in noncontrast helical computed tomography (NCT). Stone identified in the proximal right ureter (arrow), associated with ureteral wall edema (tissue rim sign) and perinephric fat stranding. A stone in the kidney is also identified (arrow head).
When we analyzed the interobserver agreement for identifying intrarenal collecting system dilatation $(\mathrm{k}=0.75)$ and stranding of perinephric fat $(\mathrm{k}=0.78)$, we found substantial agreement between the residents and the experienced physicians. When we evaluated ureteral dilatation $(\mathrm{k}=0.46)$ and stranding of ureteral fat $(0.41)$, the interobserver agreement was only moderate. This may have been due to inexperience with what constitutes ureteral dilatation and the more subjective nature of periureteric fat stranding, compared with perinephric stranding.

One advantage of our study was the short time interval between the US and CT examinations, with an average interval of four hours. This was a limitation in previous studies, in which CT and US were obtained with longer intervals between them. Shorter intervals minimize the likelihood that the stone could have passed through prior to the second examination. ${ }^{15}$

Varanelli et al. ${ }^{32}$ investigated the relationship between duration of the flank pain and frequency of secondary signs of ureteral obstruction on unenhanced helical CT. Their study demonstrated that all the secondary signs, except nephromegaly, showed significantly increased frequency as the duration of flank pain increased. In our data, there was no statistical significance between the duration of pain and the frequency of identification of secondary signs.

The limitations of our study include the fact that we did not use unenhanced plain radiography, resistive index values or color Doppler evaluation of ureteral jets to increase the accuracy of our ultrasound examinations. ${ }^{7,11,33,34}$ The relatively low prevalence of non-urinary diagnoses in our patient population may have resulted from more accurate patient screening by the referring emergency department physicians. ${ }^{11}$

\section{CONCLUSIRNS}

Different methods are available to radiologists for evaluating patients with acute renal colic, but noncontrast helical CT has overwhelmingly become the diagnostic method of choice. ${ }^{35,36}$ The findings from this study have confirmed this within a teaching hospital setting, and have also demonstrated that the learning curve for NCT is faster, by showing that the interobserver agreement between experienced abdominal radiologists and senior residents is excellent for identifying ureteral calculi, intrarenal collecting system dilatation and perinephric fat stranding. 
1. Smith RC, Rosenfield AT, Choe KA, et al. Acute flank pain: comparison of non-contrast-enhanced $\mathrm{CT}$ and intravenous urography. Radiology. 1995;194(3):789-94

2. Tamm EP, Silverman PM, Shuman WP. Evaluation of the patient with flank pain and possible ureteral calculus. Radiology 2003;228(2):319-29.

3. Sourtzis S, Thibeau JF, Damry N, Raslan A, Vandendris M, Bellemans M. Radiologic investigation of renal colic: unenhanced helical CT compared with excretory urography. AJR Am J Roentgenol. 1999;172(6): 1491-4

4. Goldman SM, Faintuch S, Ajzen SA, et al. Diagnostic value of attenuation measurements of the kidney on unenhanced helical CT of obstructive ureterolithiasis. AJR Am J Roentgenol. 2004;182(5):1251-4.

5. Lanoue MZ, Mindell HJ. The use of unenhanced helical CT to evaluate suspected renal colic. AJR Am J Roentgenol. 1997;169(6):1579-84.

6. Souza LRMF, Faintuch S, De Nicola $\mathrm{H}$, et al. A tomografia computadorizada helicoidal no diagnóstico da litíase ureteral. Rev Imagem. 2004;26(4):315-21. Available from: http://www. spr.org.br/default.aspx?pagid=ERNCOPUI\&menuid=268\# Accessed in 2007 ( $\mathrm{Feb} 13$ ).

7. Dyer RB, Zagoria RJ. Radiological evaluation of ureteral calcul and acute ureteral obstruction. In: Pollack HM, editor. Clinical urography. Philadelphia: WB Saunders; 1990. p. 2200-38.

8. Smith RC, Varanelli M. Diagnosis and management of acute ureterolithiasis: CT is truth. AJR Am J Roentgenol. 2000;175(1):3-6.

9. Patlas M, Farkas A, Fisher D, Zaghal I, Hadas-Halpern I. UItrasound vs $\mathrm{CT}$ for the detection of ureteric stones in patients with renal colic. Br J Radiol. 2001;74(886):901-4.

10. Middleton WD, Dodds WJ, Lawson TL, Foley WD. Renal calculi: sensitivity for detection with US. Radiology. 1988;167(1):239-44.

11. Sheafor DH, Hertzberg BS, Freed KS, et al. Nonenhanced helical $\mathrm{CT}$ and US in the emergency evaluation of patients with renal colic: prospective comparison. Radiology. 2000;217(3):792-7.

12. Freed KS, Paulson EK, Frederick MG, et al. Interobserver variability in the interpretation of unenhanced helical CT for the diagnosis of ureteral stone disease. J Comput Assist Tomogr. 1998;22(5):732-7.

13. Catalano O, Nunziata A, Altei F, Siani A. Suspected ureteral colic: primary helical CT versus selective helical CT after unenhanced radiography and sonography. AJR Am J Roentgenol. 2002;178(2):379-87.
14. Landis JR, Koch GG. The measurement of observer agreement for categorical data. Biometrics. 1977;33(1):159-74

15. Fowler KA, Locken JA, Duchesne JH, Williamson MR. US for detecting renal calculi with nonenhanced $\mathrm{CT}$ as a reference standard. Radiology. 2002;222(1):109-13.

16. Drach GW. Urinary lithiasis. Etiology, diagnosis and medical management. In: Walsh PC, Retik AB, Stamey TA, Vaughan ED Jr, editors. Campbell's urology. $6^{\text {th }}$ ed. Philadelphia: WB Saunders; 1992. p. 2085-156.

17. Platt JF. Urinary obstruction. Radiol Clin North Am. 1996;34(6):1113-29.

18. Sudah M, Vanninen RL, Partanen K, et al. Patients with acute flank pain: comparison of MR urography with unenhanced helical CT. Radiology. 2002;223(1):98-105.

19. Preminger GM, Vieweg J, Leder RA, Nelson RC. Urolithiasis detection and management with unenhanced spiral CT-urologic perspective. Radiology. 1998;207(2):308-9.

20. Memarsadeghi M, Heinz-Peer G, Helbich TH, et al. Unenhanced multi-detector row $\mathrm{CT}$ in patients suspected of having urinary stone disease: effect of section width on diagnosis. Radiology. 2005;235(2):530-6.

21. Katz D, Hines J, Rausch DR, et al. Unenhanced helical CT for suspected renal colic. AJR Am J Roentgenol. 1999; 173(2):425-30

22. Coll DM, Varanelli MJ, Smith RC. Relationship of spontane ous passage of ureteral calculi to stone size and location a revealed by unenhanced helical CT. AJR Am J Roentgenol. 2002;178(1):101-3.

23. Bell TV, Fenlon HM, Davison BD, Ahari HK, Hus sain S. Unenhanced helical CT criteria to differentiat distal ureteral calculi from pelvic phleboliths. Radiology. 1998;207(2):363-7.

24. Chen MY, Zagoria RJ, Saunders HS, Dyer RB. Trends in the use of unenhanced helical CT for acute urinary colic. AJR Am J Roentgenol. 1999;173(6):1447-50.

25. Smith RC, Verga M, McCarthy S, Rosenfield AT. Diagnosis of acute flank pain: value of unenhanced helical CT. AJR Am J Roentgenol. 1996;166(1):97-101.

26. Grisi G, Stacul F, Cuttin R, Rimondini A, Meduri S, Dalla Palm L. Cost analysis of different protocols for imaging a patient with acute flank pain. Eur Radiol. 2000;10(10):1620-7.

27. Levine JA, Neitlich J, Verga M, Dalrymple N, Smith RC Ureteral calculi in patients with flank pain: correlation of plain radiography with unenhanced helical CT. Radiology. 1997;204(1):27-31
28. Haddad MC, Sharif HS, Shahed MS, et al. Renal colic: diagnosis and outcome. Radiology. 1992;184(1):83-8.

29. Smith RC, Verga M, Dalrymple N, McCarthy S, Rosenfield AT. Acute ureteral obstruction: value of secondary signs on helical unenhanced CT. AJR Am J Roentgenol. 1996;167(5):1109-13.

30. Dalrymple NC, Casford B, Raiken DP, Elsass KD, Pagan RA. Pearls and pitfalls in the diagnosis of ureterolithiasis with unenhanced helical CT. Radiographics. 2000;20(2):439-47; quiz 527-8, 532 .

31. Ege G, Akman H, Kuzucu K, Yildiz S. Acute ureterolithiasis: incidence of secondary signs on unenhanced helical CT and influence on patient management. Clin Radiol. 2003;58(12):990-4.

32. Varanelli MJ, Coll DM, Levine JA, Rosenfield AT, Smith RC. Relationship between duration of pain and secondary signs of obstruction of the urinary tract on unenhanced helical CT. AJR Am J Roentgenol. 2001;177(2):325-30.

33. Svedstrom E, Alanen A, Nurmi M. Radiologic diagnosis of renal colic: the role of plain films, excretory urography and sonography. Eur J Radiol. 1990;11(3):180-3.

34. Reis-Santos JM, Reis-Santos KT. Urinary obstruction due to lithiasis. Br J Urol. 2000;26(4):360-71. Available from http:/ www.brazjurol.com.br/pdf/reis_santos_360_371.pdf. Accessed in 2007 (Feb 13).

35. Galvāo Filho MM, D'Íppolito G, Hartmann LG, et al. O valor da tomografia computadorizada helicoidal sem contraste na avaliaçăo de pacientes com dor no flanco. [The value of unenhanced helical computed tomography in the evaluation of patients with pain in the flank]. Radiol Bras. 2001;34(3):129-34.

36. Sandhu C, Anson KM, Patel U. Urinary tract stones--Part I: role of radiological imaging in diagnosis and treatment planning. Clin Radiol. 2003;58(6):415-21.

\section{Sources of funding: None}

Conflict of interest: None

Date of first submission: May 9, 2006

Last received: December 18,2006

Accepted: February 23, 2007 
AUTHOR INFIRMATILN Luis Ronan Marquez Ferreira de Souza, MD, PhD. Diagnostic Imaging Department, Universidade Federal de São Paulo - Escola Paulista de Medicina (Unifesp-EPM) São Paulo, Brazil.

Suzan Menasce Goldman, MD, PhD. Diagnostic Imaging Department, Universidade Federal de São Paulo - Escola Paulista de Medicina (Unifesp-EPM), São Paulo, Brazil.

Salomão Faintuch, MD. Diagnostic Imaging Department, Universidade Federal de São Paulo - Escola Paulista de Medicina (Unifesp-EPM), São Paulo, Brazil.

Juliano Ferreira Faria, MD. Diagnostic Imaging Department, Universidade Federal de São Paulo - Escola Paulista de Medicina (Unifesp-EPM), São Paulo, Brazil.

Daniel Bekhor, MD, PhD. Diagnostic Imaging Department Universidade Federal de São Paulo - Escola Paulisto de Medicina (Unifesp-EPM), São Paulo, Brazil.

Dario Ariel Tiferes, MD, PhD. Diagnostic Imaging Department, Universidade Federal de São Paulo - Escola Paulista de Medicina (Unifesp-EPM), São Paulo, Brazil.

Valdemar Ortiz, MD, PhD. Department of Urology, Universidade Federal de São Paulo - Escola Paulista de Medicina (Unifesp-EPM), São Paulo, Brazil.

Peter Choyke, MD, PhD. Diagnostic Radiology Department, The Clinical Center, National Institutes of Health, Bethesda, Maryland, United States.

Jacob Szejnfeld MD, PhD. Diagnostic Imaging Depart ment, Universidade Federal de São Paulo - Escola Paulista de Medicina (Unifesp-EPM), São Paulo, Brazil.

Address for correspondence:

Luis Ronan Marquez Ferreira de Souza

Rua Leopoldino de Oliveira, 2.925 - Apto. 1100

Centro - Uberaba (MG) - Brasil - CEP 38015-000

Tel. (+55 34) 3316-0997

Fax. $(+55$ 34) 3319-1442

E-mail: lvisronan@gmail.com

Copyright @ 2007, Associação Paulista de Medicina
RESUMD

Comparação entre a ultra-sonografia e a tomografia computadorizada helicoidal sem contraste em atendimento radiológico de urgência no diagnóstico da litíase ureteral em pacientes com cólica renal aguda

CONTEXTO E OBJETIVO: Estudos atuais demonstram que a tomografia computadorizada helicoidal sem contraste (TC) apresenta maior acurácia do que a ultra-sonografia (US) no diagnóstico da ureterolitíase aguda, porém poucos estudos a esse respeito foram realizados em atendimento radiológico de urgência aguda, porém, poucos estudos a esse respeito foram realizados em atendimento radiológico de urgência realizadas por residentes no diagnóstico de ureterolitíase aguda e comparar a análise da TC interpretada por residentes e radiologistas experientes.

TIPO DE ESTUDO E LOCAL: Estudo prospectivo de 52 pacientes com cólica renal aguda, que foram submetidos a exame de US seguido de TC em período máximo de oito horas no Hospital São Paulo.

MÉTODOS: Os exames de US foram realizados por médicos residentes e conferidos pelos preceptores, já os de TC foram analisados por outro residente e posteriormente analisados por três radiologistas independentes.

RESULTADOS: Nos 52 pacientes analisados foram encontrados 40 cálculos ureterais na TC (77\%). A US apresentou uma sensibilidade de $22 \%$ e especificidade de $100 \%$, que aumentou para $73 \%$ e $82 \%$ respectivamente, quando se associou a identificação da dilatação do sistema coletor. A TC analisada pelo respectivamente, quando se associou a identificação da dilałação do sistema coletor. A TC analisada pelo
residente e pelos radiologistas apresentou uma excelente correlação para identificação do cálculo ureteral, para heterogeneidade da gordura peri-renal e para dilatação do sistema coletor.

CONCLUSÕES: A US realizada pelos residentes tem menor sensibilidade no diagnóstico da litíase ureteral, quando comparada à TC, mesmo quando associada à presença de dilatação do sistema coletor. Residentes e radiologistas especialistas apresentaram excelente concordância no diagnóstico de litíase ureteral.

PALAVRAS-CHAVE: Tomografia computadorizada espiral. Ultra-sonografia. Cálculos ureterais. Litíase. Dor no flanco. 